\title{
Role of Peripartum Dietary Propylene Glycol or Protected Fats on Metabolism and Early Postpartum Ovarian Follicles
}

\author{
U. Moallem, ${ }^{* 1}$ M. Katz, ${ }^{*} \dagger$ H. Lehrer, ${ }^{*}$ L. Livshitz, ${ }^{*}$ and S. Yakoby ${ }^{*}$ \\ ${ }^{*}$ Department of Dairy Cattle, Institute of Animal Sciences, Volcani Center, P.O. Box 6, Bet-Dagan, 50250 Israel \\ †Department of Animal Science, Faculty of Agriculture, Hebrew University, Rehovot, 76-100 Israel
}

\begin{abstract}
Eighty multiparous cows were used to test the effects of feeding a supplement containing 55\% dry propylene glycol (PGLY), prilled fat (PrFA) containing a low proportion of unsaturated fatty acids (FA), or calcium soaps of long-chain FA (CaLFA) containing a high proportion of unsaturated FA on energy balance (EB), blood metabolites, and early postpartum (PP) ovarian follicles. Dry cows (256 d pregnant) were divided into 6 groups and began the following dietary treatments: 1) control group, fed a dry cow diet and fed a lactating cow diet PP; 2) PGLY group, diet supplemented with $500 \mathrm{~g} / \mathrm{d}$ per cow of dry PGLY prepartum through $21 \mathrm{~d}$ in milk; 3) PrFA:control group, diet supplemented with $230 \mathrm{~g} /$ d per cow of PrFA prepartum and fed the control diet PP; 4) PrFA:PrFA group, diet supplemented with 230 g/d per cow of PrFA prepartum through $21 \mathrm{~d}$ in milk; 5) CaLFA:control, supplemented with $215 \mathrm{~g} / \mathrm{d}$ per cow of CaLFA prepartum and fed the control diet PP; 6) CaLFA:CaLFA, supplemented with $215 \mathrm{~g} / \mathrm{d}$ per cow of CaLFA prepartum through $21 \mathrm{~d}$ in milk. Follicular fluid was aspirated from follicles $\geq 6 \mathrm{~mm}$ on $\mathrm{d} 12 \mathrm{PP}$. The daily average calculated EB during the first $21 \mathrm{~d}$ in milk was lower in the PrFA:PrFA (-4.16 Mcal/d) and CaLFA:CaLFA (-3.64 Mcal/d) groups than in the control (-1.71 Mcal/d) and PGLY (-2.19 Mcal/d) groups. Postpartum plasma $\beta$-hydroxybutyrate was higher, and insulin concentrations were lower in the PrFA:PrFA $(6.2 \mathrm{mg} / \mathrm{dL}$ and $126.1 \mathrm{pg} / \mathrm{mL}$, respectively) and CaLFA:CaLFA $(7.0 \mathrm{mg} / \mathrm{dL}$ and $130.7 \mathrm{pg} / \mathrm{mL})$ groups than in the control $(4.5 \mathrm{mg} / \mathrm{dL}$ and $274.5 \mathrm{pg} / \mathrm{mL})$ and PGLY ( $4.3 \mathrm{mg} / \mathrm{dL}$ and $272.6 \mathrm{pg} / \mathrm{mL}$ ) groups, whereas nonesterified FA concentrations were higher only than the control group. Postpartum nonesterified FA were $21 \%$ lower and insulin plasma concentrations were $86 \%$ higher in the CaLFA:control group as compared with the PrFA:control group. The progesterone concentrations in the follicular fluid of estradiol-active follicles
\end{abstract}

Received June 29, 2006.

Accepted November 15, 2006.

${ }^{1}$ Corresponding author: uzim@volcani.agri.gov.il were higher in the CaLFA:CaLFA $(200.7 \mathrm{ng} / \mathrm{mL})$ group than in all other groups ( 57.3 to $92.4 \mathrm{ng} / \mathrm{mL}$ ), and androstenedione and estradiol concentrations were higher (54.2 and $1,049.1 \mathrm{ng} / \mathrm{mL}$, respectively) than in the PGLY (15.5 and $440.1 \mathrm{ng} / \mathrm{mL}$ ), PrFA:control (22.6 and $314.1 \mathrm{ng} / \mathrm{mL}$ ), and CaLFA:control (17.5 and $451.9 \mathrm{ng} /$ $\mathrm{mL}$ ) groups. In conclusion, supplementation of protected fat during the peripartum period negatively affected the EB status of the cows. Neither fat supplementation nor PGLY influenced the development of ovarian follicles during the early PP period, but feeding fat containing a high ratio of unsaturated FA (CaLFA) increased progesterone concentrations in estradiol-active follicles that were aspirated at $12 \mathrm{~d}$ in milk.

Key words: transition cow, unsaturated fatty acid, propylene glycol, follicle

\section{INTRODUCTION}

The transition from late pregnancy to early lactation is a critical period, and optimal hepatic function is central to lactational and reproductive performance. During the transition period, mobilization of body lipid reserves occurs, which leads to increased plasma NEFA. Nonesterified fatty acids (FA) are associated with liver triglyceride accumulation and ketone production, which are related to delayed ovulation, estrus, and pregnancy (Jorritsma et al., 2000). A correlation exists between the concentrations of NEFA in plasma and in follicular fluid (FF), which could explain possible harmful effects of NEFA on either granulosa cells or the oocyte (Jorritsma et al., 2004).

Previous studies examined the differences between supplementing the diets of dairy cows with saturated FA and unsaturated FA on their intake and metabolism. Drackley et al. (1992) suggested that increasing the postruminal unsaturated FA could affect gastrointestinal motility and therefore DMI and milk production. Infusing unsaturated FA into the abomasum decreased DMI and tended to decrease yields of milk and milk fat compared with abomasal infusion of saturated FA (Bremmer et al., 1998).

In recent years, there has been growing interest in improving metabolic and reproductive measures by 
feeding nutritional supplements to dairy cows. Staples et al. (1998) summarized several studies showing mixed results of supplementing the diets of lactating cows with fats early postpartum (PP). The most positive effects on reproduction were from feeding calcium soaps of long-chain FA. Feeding fats to early PP cows alleviated some of the adverse effects of bST administration, but not through improving the energy balance (EB; Moallem et al., 1997). Mattos et al. (2000) suggested that fat supplementation affects fertility by providing high quantities of unsaturated FA, and Robinson et al. (2002) demonstrated that dietary polyunsaturated FA can influence both ovarian and uterine functions in cows. The effects of supplemental lipids on early PP follicular development remain largely undocumented for high-producing cows (Beam and Butler, 1998).

Another strategy to improve the metabolic status of periparturient cows is by supplying propylene glycol (PGLY), which is a glucogenic precursor. Both insulin and IGF-I concentrations decline prior to parturition and are suboptimal in early lactation (Beam and Butler, 1999). Although PGLY administration makes a small positive contribution to energy status, its main benefit derives from bolus administration that increases insulin secretion (Christensen et al., 1997). Few studies have examined the effects of PGLY on reproduction in dairy cows (Miyoshi et al., 2001; Hoedemaker et al., 2004). Miyoshi et al. (2001) reported that the first ovulation PP occurred earlier when PGLY was drenched daily from $\mathrm{d} 7$ to 42 , presumably because of increased plasma insulin. On the other hand, Hoedemaker et al. (2004) found no effects of PGLY supplementation on the conception rate and overall pregnancy rate. Characterization of follicular development prior to the first ovulation PP and examination of the associated levels of EB and metabolic hormones are important steps toward understanding the metabolic constraints on PP ovarian activity (Beam and Butler, 1998).

The objectives of the present experiment were 1) to investigate the effects on cow metabolism and the quality of ovarian follicles in the early PP period of peripartum dietary supplements containing either 55\% dry PGLY, prilled fat (PrFA) containing a low proportion of unsaturated FA, or calcium soaps of long-chain FA (CaLFA) containing a high proportion of unsaturated FA; and 2) to examine the effects on PP performance of feeding fats only during the prepartum period.

\section{MATERIALS AND METHODS}

\section{Cows and Treatments}

The experiment protocol of the study was approved by the Volcani Center Animal Care Committee and was conducted at the Volcani Center experimental farm in
Table 1. Ingredients and chemical composition of the basal lactating cow diet

\begin{tabular}{lc}
\hline Item & \% of DM \\
\hline Ingredient & \\
Corn grain, ground & 15.5 \\
Barley grain, rolled & 18.7 \\
Rapeseed meal & 1.0 \\
Corn gluten meal & 3.2 \\
Soybean meal & 5.2 \\
Sunflower meal & 1.8 \\
Corn gluten feed & 7.7 \\
Cottonseed & 4.7 \\
Wheat silage & 12.5 \\
Corn silage & 12.0 \\
Dried distillers grains & 3.9 \\
Molasses & 0.6 \\
Vetch hay & 2.2 \\
Oat hay & 8.9 \\
Soybean oil & 0.1 \\
Salt & 1.4 \\
Calcium bicarbonate & 0.5 \\
Vitamins and minerals ${ }^{1}$ & 0.1 \\
Chemical composition & \\
NE ${ }^{2}{ }^{2}$ Mcal/kg & 1.725 \\
CP & 17.0 \\
RUP & 6.0 \\
ADF & 19.4 \\
NDF & 31.7 \\
NDF-forage & \\
Ether extract & 18.7 \\
Ca & 3.55 \\
P & 0.9 \\
\hline
\end{tabular}

${ }^{1}$ Contained 20,000,000 IU of vitamin $\mathrm{A} / \mathrm{kg}, 2,000,000 \mathrm{IU}$ of vitamin $\mathrm{D} / \mathrm{kg}, 15,000 \mathrm{IU} / \mathrm{kg}$ of vitamin E, $6,000 \mathrm{mg} / \mathrm{kg}$ of $\mathrm{Mn}, 6,000 \mathrm{mg} / \mathrm{kg}$ of $\mathrm{Zn}, 2,000 \mathrm{mg} / \mathrm{kg}$ of $\mathrm{Fe}, 1,500 \mathrm{mg} / \mathrm{kg}$ of $\mathrm{Cu}, 120 \mathrm{mg} / \mathrm{kg}$ of I, $50 \mathrm{mg} / \mathrm{kg}$ of Se, and $20 \mathrm{mg} / \mathrm{kg}$ of Co.

${ }^{2}$ Calculated using NRC (2001) guidelines.

${ }^{3}$ Neutral detergent fiber from forage and nonforage sources.

${ }^{4}$ Neutral detergent fiber from forage sources.

Bet Dagan, Israel. The study was conducted from September to April to avoid effects of heat stress. Eighty multiparous Israeli-Holstein dry cows, $249 \mathrm{~d}$ pregnant, were group-housed in shaded outdoor pens with adjacent outside yards, which were equipped with a realtime electronic individual feeding system. Each station was equipped with an individual identification system (S.A.E Afikim, Kibbutz Afikim, Israel) that allowed each cow to enter a specific station and which automatically recorded each meal. After $7 \mathrm{~d}$ of adaptation, at $256 \mathrm{~d}$ of pregnancy, the cows were divided into 6 groups of 13 to 14 cows each to begin treatment. The cows were stratified on the basis of previous lactation milk and fat, parity, BW, and BCS assigned to treatments. All treatments commenced at $256 \mathrm{~d}$ of pregnancy as follows: 1) Cows in the control group were fed a dry cow diet and $\mathrm{PP}$ were fed a lactating cow diet (Table 1 ) according to NRC (2001) recommendations. 2) Cows in the PGLY group were fed a prepartum dry cow diet and $\mathrm{PP}$ a lactating cow diet supplemented with $909 \mathrm{~g} / \mathrm{d}$ per cow 
Table 2. Proglyc $55^{1}$ composition and content

\begin{tabular}{lc}
\hline Item & \% of DM \\
\hline CP & 4.0 \\
Ether extract & 1.5 \\
1,2-Propanediol & 55.0 \\
Carbohydrates & 32.0 \\
OM & 95.0 \\
Ca & 2.6 \\
P & 0.4 \\
\hline
\end{tabular}

${ }^{1}$ Kimtec (Heijningen, the Netherlands).

of glucogenic additive containing 55\% dry PGLY (ProGlyc 55; Kimtec, Heijningen, the Netherlands), equal to $500 \mathrm{~g} / \mathrm{d}$ of pure PGLY, prepartum through 21 DIM. 3) Those in PrFA:control group were fed a dry cow diet supplemented with $230 \mathrm{~g} / \mathrm{d}$ per cow of PrFA (Energy Booster 100; Milk Specialties, Dundee, IL), and PP were fed the control diet. 4) Those in the PrFA:PrFA group were fed a dry cow diet supplemented with $230 \mathrm{~g} / \mathrm{d}$ per cow of PrFA, and PP were fed a lactating diet supplemented with $230 \mathrm{~g} / \mathrm{d}$ per cow of PrFA through 21 DIM. 5) Cows in the CaLFA:control group were fed a dry cow diet supplemented with $215 \mathrm{~g} / \mathrm{d}$ per cow of CaLFA (Megalac-R; Church \& Dwight, Princeton, NJ) and PP were fed the control diet. 6) And those in the CaLFA:CaLFA group were fed a dry cow diet supplemented with $215 \mathrm{~g} / \mathrm{d}$ per cow of CaLFA and PP were fed a lactating diet supplemented with $215 \mathrm{~g} / \mathrm{d}$ per cow of CaLFA through 21 DIM. The dry cow diet was based on 12 to $12.5 \% \mathrm{CP}, 42$ to $49 \%$ NDF (DM basis), and $1.49 \mathrm{NE}_{\mathrm{L}} \mathrm{Mcal} / \mathrm{kg}$ of DM. The composition and content of the ProGlyc 55 are presented in Table 2, and the FA profiles of Energy Booster 100 and Megalac-R are presented in Table 3 . The diets were formulated to be isoenergetic, except for PGLY, which was higher by 0.78 $\mathrm{Mcal} / \mathrm{d}$ per cow. The energy contents of all supplements that were used in this study were calculated according to the manufacturer's specifications, which were 2.5, 6.0, and 6.6 NE $\mathrm{L}_{\mathrm{L}} \mathrm{Mcal} / \mathrm{kg}$ of DM for ProGlyc 55, Energy Booster 100, and Megalac-R, respectively.

Daily individual intake was recorded. The cows were fed once a day at $1100 \mathrm{~h}$ and the fat supplements were

Table 3. Fat supplement (Energy Booster 100 and Megalac-R $)^{1}$ fatty acid profiles (\% of total)

\begin{tabular}{lcc}
\hline Fatty acid & Energy Booster $100, \%$ & Megalac-R, $\%$ \\
\hline $16: 0$ & 28.20 & 17.40 \\
$18: 0$ & 51.20 & 2.10 \\
$18: 1$ & 8.39 & 33.63 \\
$18: 2$ & 1.53 & 30.50 \\
$18: 3$ & 0.13 & 2.40 \\
Other fatty acids & 10.55 & 13.97 \\
\hline
\end{tabular}

${ }^{1}$ Energy Booster 100 (Milk Specialties, Dundee, IL); Megalac-R (Church \& Dwight, Princeton, NJ). individually hand-mixed into the upper one-third of the TMR. The PGLY supplement was hand-mixed with the TMR and offered to each cow $5 \mathrm{~h}$ after the regular feeding $(1600 \mathrm{~h})$ to extend the insulin release and its action beyond the normal feeding-associated insulin release period.

The cows were weighed automatically 3 times daily after each milking with a walking electronic scale, and milk production was recorded electronically. Body condition score (scale of 1 to 5) was determined weekly by a technician. Milk solids content was determined from 3 consecutive milkings twice during the first 21 DIM. Milk fat, protein, and lactose were determined by infrared analysis at the Israeli Cattle Breeders Association (Caesarea, Israel).

Three times weekly (on Sunday, Tuesday, and Thursday) until 21 DIM, blood samples were collected from the jugular vein into vacuum tubes containing lithium heparin (Becton Dickinson Systems, Cowley, UK). Additional blood samples were collected in tubes containing lithium chloride and L-iodoacetate (BD Vacutainer; Belliver Industrial Estate, Plymouth, UK) for glucose analysis. The blood samples were collected after the morning milking at $0800 \mathrm{~h}$, and plasma was separated immediately from blood samples and stored at $-18^{\circ} \mathrm{C}$ until analysis. All cows were examined 7 to 10 $\mathrm{d}$ after calving by a veterinarian and clinical events were recorded.

\section{Ovarian Screening and Follicular Fluid Aspiration}

Ovaries of the cows were monitored at 8 and 10 DIM by linear array ultrasonography (Scanner 200; Pie Medical, Maastricht, the Netherlands), and the number and diameter of follicles $\geq 6 \mathrm{~mm}$ were recorded. On d $12 \mathrm{PP}$, cows were sedated with an i.m. injection of $20 \mathrm{mg}$ of Rompun (XYL-M2 Veterinary, xylazine base, $20 \mathrm{mg} /$ $\mathrm{mL}$; VMD, Arendonk, Belgium) and were given a local anesthesia of $100 \mathrm{mg}$ of lidocaine $\mathrm{HCl}$ (Esracain $2 \%$, $200 \mathrm{mg} / 10 \mathrm{~mL}$; Rafa Laboratories, Jerusalem, Israel) injected epidurally between the last sacral and first caudal vertebrae. Ovaries were examined, the diameters of the large follicles were measured, and follicles $\geq 6 \mathrm{~mm}$ were aspirated transvaginally; each follicle was aspirated into a single tube, centrifuged, and the FF stored at $-18^{\circ} \mathrm{C}$ until analysis.

\section{EB Calculation}

Individual EB was calculated daily from parturition until 21 DIM. The EB was calculated according to NRC (2001) guidelines and according to Beam and Butler (1998) as follows: 


$$
\begin{gathered}
\mathrm{NE}_{\mathrm{c}}=\mathrm{NE}_{\mathrm{L}} \text { per kg of } \mathrm{DM} \times \mathrm{DMI} ; \\
\mathrm{NE}_{\mathrm{L}}=\text { milk }(\mathrm{kg}) \times[0.0929 \times(\text { fat } \%)+0.0547 \\
\times(\mathrm{CP} \%)+0.0395 \times(\text { lactose } \%)] \\
\mathrm{NE}_{\mathrm{R}}=\mathrm{BW}^{0.75}(0.08) \times 1.1+\mathrm{NE}_{\mathrm{L}} ; \\
\mathrm{EB}=\mathrm{NE}_{\mathrm{C}}-\mathrm{NE}_{\mathrm{R}}
\end{gathered}
$$

where $\mathrm{NE}_{\mathrm{C}}$ is the net energy consumed and $\mathrm{NE}_{\mathrm{R}}$ is the net energy required.

\section{Chemical Analysis}

Total mixed rations were sampled weekly and DM, $\mathrm{CP}, \mathrm{NDF}, \mathrm{ADF}, \mathrm{Ca}$, and $\mathrm{P}$ were determined. Feed samples were dried at $65^{\circ} \mathrm{C}$ for $24 \mathrm{~h}$ and then ground to pass through a 1.0-mm screen (Retsch S-M-100; Retsch $\mathrm{GmbH}$, Haan, Germany). The ground samples were dried at $100^{\circ} \mathrm{C}$ for $24 \mathrm{~h}$ and analyzed for $\mathrm{N}$ (AOAC, 1990; Method 984.13), Ca (AOAC, 1990; Method 935.13), and P (AOAC, 1990; Method 964.06). Neutral detergent fiber and $\mathrm{ADF}$ contents were determined with Ankom equipment (Ankom Technology, Fairport, NY; NDF, using $\alpha$-amylase and sodium sulfite). Values for $\mathrm{NE}_{\mathrm{L}}$ were calculated using the NRC values (NRC, 2001). Plasma glucose was determined by a glucose reagent kit (glucose UV $10 \times 50 \mathrm{~mL}$; Raichem, San Diego, CA). Plasma BHBA was determined by a kit (Ranbut D-3-hydroxybutyrate; Randox, Crumlin, UK). Plasma NEFA was determined by a kit (Wako NEFA C test kit; Wako Chemicals GmbH, Neuss, Germany). Plasma insulin was determined by RIA (Diagnostic Products, Los Angeles, $\mathrm{CA}$ ). The intra- and interassay coefficients of variation for the insulin assay were 7.2 and $5.1 \%$, respectively.

Concentrations of progesterone $\left(\mathbf{P}_{4}\right)$ and estradiol $\left(\mathbf{E}_{2}\right)$ in FF were determined by RIA (Diagnostic Products), as were androstenedione $\left(\mathbf{A}_{4}\right)$ concentrations (Diagnostic Systems Laboratories, Webster, TX). The intra- and interassay coefficients of variation for the $\mathrm{P}_{4}$ assay were 9.9 and $8.6 \%$, respectively. The intra- and interassay coefficients of variation for the $\mathrm{E}_{2}$ assay were 5 and $3 \%$, and for the $\mathrm{A}_{4}$ assay were 6.3 and $4.3 \%$, respectively.

\section{Statistical Analysis}

Continuous variables (milk, DMI, and blood metabolites) were analyzed as repeated measurements using Proc Mixed of SAS (version 8.1; SAS Institute, 2000). For all variables that were analyzed as repeated measurements, the average values for every $3 \mathrm{~d}$ were calculated and used for the statistical test. The interactions of treatment $\times$ parity, treatment $\times$ DIM, parity $\times$ DIM, and treatment $\times$ parity $\times$ DIM were tested for each dependent variable and were not significant for any detected variable; therefore, they were excluded from the model.

The final model used was

$$
\begin{gathered}
\mathrm{Y}_{\mathrm{ijklm}}=\mu+\mathrm{T}_{\mathrm{i}}+\mathrm{L}_{\mathrm{j}}+\mathrm{C}(\mathrm{T} \times \mathrm{L})_{\mathrm{ijk}}+\mathrm{DIM}_{\mathrm{ijkl}}+\mathrm{DIM}_{\mathrm{ijkl}} \\
\times \mathrm{DIM}_{\mathrm{ijkl}}+\mathrm{DIM}_{\mathrm{ijkl}} \times \mathrm{DIM}_{\mathrm{ijkl}} \times \mathrm{DIM}_{\mathrm{ijkl}}+\mathrm{e}_{\mathrm{ijklm}},
\end{gathered}
$$

where $\mu$ is the overall mean, $T_{i}$ is the treatment effect (where $\mathrm{i}$ is 1 to 6 ), $\mathrm{L}_{\mathrm{j}}$ is parity (where $\mathrm{j}$ is 2 or $>2$ ), $\mathrm{C}(\mathrm{T}$ $\times \mathrm{L})_{\mathrm{ijk}}$ is $\operatorname{cow}_{\mathrm{k}}$ nested in treatment $\mathrm{i}_{\mathrm{i}}$ and cow nested in parity $_{\mathrm{j}}, \mathrm{DIM}_{\mathrm{j} \mathrm{jkl}}$ is DIM as a continuous variable, and $\mathrm{e}_{\mathrm{ijk} l \mathrm{~m}}$ is the random residual.

Whenever the quadratic or cubic effects were not significant, they were excluded from the model and the model was rerun. The differences in least squares means between treatments of the Proc Mixed procedure were used for comparative effects.

Other variables were analyzed using the GLM procedure of SAS. Least squares means and adjusted SEM are presented in the tables, and $P<0.05$ was accepted as significant unless otherwise stated.

\section{RESULTS}

\section{DMI and Milk Production}

The average DMI during the first $21 \mathrm{DIM}$ is presented in Table 4 and Figure 1. The average daily DMI until 21 DIM in the PrFA:PrFA, CaLFA:control, and CaLFA:CaLFA groups were lower than in the control group $(P<0.02)$. The average daily energy intake $(\mathbf{E I})$ during 21 DIM in the CaLFA:control group was significantly lower than in the control, PGLY, and PrFA:control groups $(P<0.01)$. Analysis of the DMI from calving through 14 DIM showed that the DMI of the control group was similar to that of the PGLY group and was higher than in the PrFA:PrFA, CaLFA:control, and CaLFA:CaLFA groups $(P<0.04)$.

Milk production results are presented in Table 4. Milk production until 21 DIM in the CaLFA:control group was similar to that of the control group but lower than all other groups $(P<0.05)$. No differences were observed in fat percentage among groups. The fat yield in the CaLFA:control group was lower than in all other groups $(P<0.05)$. The protein percentage in the CaLFA:CaLFA group was lower than in the control and PGLY groups $(P<0.05)$. Fat-corrected milk $(3.5 \%)$ was lower in the CaLFA:control group than in all other groups $(P<0.05)$. The gross efficiency of FCM $(3.5 \%)$ from DMI was higher in the PrFA:PrFA and CaLFA:CaLFA groups than in the control and CaLFA:control groups $(P<0.05)$. The efficiency of EI for milk energy was not different among groups. 
Table 4. Least squares means of DMI, milk production, efficiency, and energy balance from calving to 21 $\mathrm{DIM}^{1}$

\begin{tabular}{lccccccc}
\hline & \multicolumn{7}{c}{ Treatment $^{1}$} \\
\cline { 2 - 8 } Item & Control & PGLY & $\begin{array}{c}\text { PrFA: } \\
\text { control }\end{array}$ & $\begin{array}{c}\text { PrFA: } \\
\text { PrFA }\end{array}$ & $\begin{array}{c}\text { CaLFA: } \\
\text { control }\end{array}$ & $\begin{array}{c}\text { CaLFA: } \\
\text { CaLFA }\end{array}$ & SEM \\
\hline Cows, n & 14 & 13 & 13 & 13 & 13 & 14 & \\
DMI, kg & $19.8^{\mathrm{a}}$ & $19.7^{\mathrm{ab}}$ & $19.5^{\mathrm{abc}}$ & $18.4^{\mathrm{bcd}}$ & $18.2^{\mathrm{d}}$ & $18.3^{\mathrm{cd}}$ & 0.46 \\
Energy intake, Mcal & $34.4^{\mathrm{a}}$ & $34.6^{\mathrm{a}}$ & $33.8^{\mathrm{a}}$ & $32.7^{\mathrm{ab}}$ & $31.6^{\mathrm{b}}$ & $32.6^{\mathrm{ab}}$ & 0.80 \\
Milk, kg & $33.4^{\mathrm{ab}}$ & $34.7^{\mathrm{a}}$ & $35.4^{\mathrm{a}}$ & $35.6^{\mathrm{a}}$ & $31.9^{\mathrm{b}}$ & $35.4^{\mathrm{a}}$ & 0.86 \\
Fat, \% & 4.13 & 4.03 & 4.00 & 4.00 & 3.89 & 3.86 & 0.16 \\
Fat, kg & $1.37^{\mathrm{a}}$ & $1.40^{\mathrm{a}}$ & $1.40^{\mathrm{a}}$ & $1.39^{\mathrm{a}}$ & $1.20^{\mathrm{b}}$ & $1.34^{\mathrm{a}}$ & 0.05 \\
Protein, \% & $3.23^{\mathrm{a}}$ & $3.19^{\mathrm{a}}$ & $3.18^{\mathrm{ab}}$ & $3.06^{\mathrm{ab}}$ & $3.16^{\mathrm{ab}}$ & $3.00^{\mathrm{b}}$ & 0.06 \\
Protein, kg & $1.08^{\mathrm{a}}$ & $1.10^{\mathrm{a}}$ & $1.11^{\mathrm{a}}$ & $1.08^{\mathrm{a}}$ & $0.98^{\mathrm{b}}$ & $1.06^{\mathrm{ab}}$ & 0.03 \\
Lactose, \% & $5.05^{\mathrm{a}}$ & $4.91^{\mathrm{ab}}$ & $4.96^{\mathrm{ab}}$ & $4.93^{\mathrm{ab}}$ & $5.00^{\mathrm{ab}}$ & $4.82^{\mathrm{b}}$ & 0.06 \\
$3.5 \%$ FCM, kg & $36.5^{\mathrm{a}}$ & $37.6^{\mathrm{a}}$ & $38.1^{\mathrm{a}}$ & $37.9^{\mathrm{a}}$ & $33.5^{\mathrm{b}}$ & $37.1^{\mathrm{a}}$ & 1.14 \\
$3.5 \%$ FCM/DMI, kg/kg & $1.86^{\mathrm{b}}$ & $1.99^{\mathrm{ab}}$ & $2.03^{\mathrm{ab}}$ & $2.13^{\mathrm{a}}$ & $1.90^{\mathrm{b}}$ & $2.11^{\mathrm{a}}$ & 0.07 \\
Milk energy $/ \mathrm{energy} \mathrm{intake,} \mathrm{Mcal/Mcal}$ & 1.07 & 0.77 & 0.80 & 0.82 & 0.75 & 0.77 & 0.14 \\
Calculated energy balance, Mcal/d & $-1.71^{\mathrm{a}}$ & $-2.19^{\mathrm{ab}}$ & $-3.12^{\mathrm{bc}}$ & $-4.16^{\mathrm{c}}$ & $-2.36^{\mathrm{ab}}$ & $-3.64^{\mathrm{c}}$ & 0.43 \\
\hline
\end{tabular}

${ }^{\mathrm{a}-\mathrm{e}}$ Within rows, means with different letter superscripts are different $(P<0.05)$.

${ }^{1}$ Treatments: Cows were fed from $256 \mathrm{~d}$ of pregnancy a dry cow ration and postpartum were fed a lactating cow diet (control); propylene glycol (PGLY); prilled fat:control (PrFA:control); PrFA:PrFA; calcium soaps of long-chain fatty acids:control (CaLFA control); or CaLFA:CaLFA.

${ }^{2}$ Milk energy was calculated according to NRC (2001) guidelines: milk energy $=$ milk $(\mathrm{kg}) \times[0.0929 \times($ fat $\%)+0.0547 \times(\mathrm{CP} \%)+0.0395 \times($ lactose $\%)]$.

\section{$B W, B C S$, and $E B$}

No differences in BW changes were observed among groups (data not shown). The average BCS at calving were $3.17,3.22,3.19,3.31,3.31$, and 3.40 (pooled SEM = 0.027) for the control, PGLY, PrFA:control, PrFA:PrFA, CaLFA:control, and CaLFA:CaLFA groups, respectively. The average BCS units lost from calving to wk 4 of lactation were $0.56,0.70,0.71,0.74,0.75$, and 0.93 (pooled SEM = 0.09) for the control, PGLY, PrFA:control, PrFA:PrFA, CaLFA:control, and CaLFA:CaLFA groups, respectively. The BCS units lost in the CaLFA:CaLFA group were higher than those in the control and PGLY groups $(P<0.05)$.

The results of the daily average EB are presented in Table 4 and Figure 1. The calculated EB for each cow was used for determination of the average EB during the first 21 DIM. The daily average calculated EB during 21 DIM in the control group was less negative than those of the PrFA:control, PrFA:PrFA, and CaLFA:CaLFA groups $(P<0.01)$. Analysis of the daily average calculated EB for the first 12 DIM showed that it was higher in the control group than in all other groups $(P<0.05)$.

\section{Plasma Metabolites}

Postpartum plasma metabolite concentrations during the early PP period are presented in Table 5 and Figure 2. The plasma glucose concentrations in the PGLY group were similar to that of the control group but were higher than in all other groups $(P<0.05)$.
Plasma NEFA concentrations were higher in the PrFA:PrFA and CaLFA:CaLFA treatment groups than in the control group $(P<0.05)$. Plasma NEFA concentrations in the PrFA:control group were $21 \%$ higher than in the CaLFA:control group $(P<0.05)$. Plasma BHBA concentrations in the control and PGLY groups were similar to that of the CaLFA:control group and were lower than in all other groups $(P<0.05)$. The highest plasma BHBA concentrations were in the CaLFA:CaLFA group; they were similar to those of the PrFA:PrFA group and higher than those in the control, PGLY, PrFA:control, and CaLFA:control groups $(P<$ 0.05). The plasma insulin concentrations were similar among the control, PGLY, and CaLFA:control groups and were higher than in the PrFA:control, PrFA:PrFA, and CaLFA:CaLFA groups $(P<0.006$; Figure 3$)$. The frequency of PP clinical events was summarized, and no differences in the occurrence of clinical disorders were observed among groups (data not shown).

\section{FF Aspiration at 12 DIM}

Because of the large uterus at 8 DIM and difficulties in monitoring the ovaries at that time, samples of the cows were screened at $8(n=39), 10(n=53)$, and 12 DIM $(n=80)$. Eighty-two percent of the ovaries of the cows screened by ultrasound at 8 DIM had at least 1 follicle $\geq 6 \mathrm{~mm}$, with an average of 1.75 follicles $\geq 6 \mathrm{~mm}$. At 10 DIM, ovaries in $94 \%$ of the cows had at least 1 follicle $\geq 6 \mathrm{~mm}$, with an average of 1.58 follicles per cow. No significant differences in the appearance of follicles 



Figure 1. Least squares means of (A) DMI and (B) daily average calculated energy balance (EB) to 21 DIM of cows fed from $256 \mathrm{~d}$ of pregnancy a dry cow ration and postpartum fed a lactating cow diet: control ( $\times$ ); propylene glycol (PGLY, $\mathbf{0})$ : prilled fat:control (PrFA:control, A); PrFA:PrFA $(\triangle)$; calcium soaps of long-chain fatty acids:control (CaLFA:control, O); or CaLFA:CaLFA (O). The pooled SEM value for EB was $0.43 \mathrm{Mcal} / \mathrm{d}$.

$\geq 6 \mathrm{~mm}$ were observed between $\mathrm{d} 8$ and $10 \mathrm{PP}$, and no differences were observed among groups. At 12 DIM, the FF from follicles $\geq 6 \mathrm{~mm}$ was aspirated from $94 \%$ (66 out of 70) of the monitored cows. In 4 cows, no follicles $\geq 6 \mathrm{~mm}$ were found in the ovaries, and in 10 cows, the FF aspiration at 12 DIM failed because of technical problems or the clinical status of the cows.
The concentrations of $\mathrm{P}_{4}, \mathrm{~A}_{4}$, and $\mathrm{E}_{2}$ in $\mathrm{FF}$ aspirated at 12 DIM were determined. Follicles were classified as $\mathrm{E}_{2}$-active whenever the $\mathrm{E}_{2}: \mathrm{P}_{4}$ ratio in $\mathrm{FF}$ was $>1$ and were regarded as $\mathrm{E}_{2}$-inactive whenever the $\mathrm{E}_{2}: \mathrm{P}_{4}$ ratio was $\leq 1$. Seventy-one out of 90 (79\%) follicles that were aspirated at 12 DIM were defined as $\mathrm{E}_{2}$-active, and these follicles were used for further analysis. The over- 
Table 5. Least squares means of postpartum plasma metabolite and insulin concentrations

\begin{tabular}{|c|c|c|c|c|c|c|c|}
\hline \multirow[b]{2}{*}{ Item } & \multicolumn{6}{|c|}{ Treatment $^{1}$} & \multirow[b]{2}{*}{ SEM } \\
\hline & Control & PGLY & $\begin{array}{l}\text { PrFA: } \\
\text { control }\end{array}$ & $\begin{array}{l}\text { PrFA: } \\
\text { PrFA }\end{array}$ & $\begin{array}{l}\text { CaLFA: } \\
\text { control }\end{array}$ & $\begin{array}{c}\text { CaLFA: } \\
\text { CaLFA }\end{array}$ & \\
\hline Cows, $\mathrm{n}$ & 14 & 13 & 13 & 13 & 13 & 14 & \\
\hline Glucose, mg/dL & $61.1^{\mathrm{ab}}$ & $63.3^{\mathrm{a}}$ & $58.8^{\mathrm{b}}$ & $59.3^{\mathrm{b}}$ & $60.0^{\mathrm{b}}$ & $59.5^{\mathrm{b}}$ & 1.2 \\
\hline NEFA, $\mu \mathrm{Eq} / \mathrm{L}$ & $423.3^{\mathrm{bc}}$ & $514.8^{\mathrm{abc}}$ & $607.3^{\mathrm{ab}}$ & $608.3^{\mathrm{a}}$ & $477.5^{\mathrm{c}}$ & $620.8^{\mathrm{a}}$ & 44.2 \\
\hline BHBA, $\mathrm{mg} / \mathrm{dL}$ & $4.5^{\mathrm{d}}$ & $4.3^{\mathrm{d}}$ & $5.8^{\mathrm{bc}}$ & $6.2^{\mathrm{ab}}$ & $4.9^{\mathrm{cd}}$ & $7.0^{\mathrm{a}}$ & 0.4 \\
\hline Insulin, pg/mL & $274.5^{\mathrm{a}}$ & $272.6^{\mathrm{a}}$ & $133.1^{b}$ & $126.1^{b}$ & $247.6^{\mathrm{a}}$ & $130.7^{\mathrm{b}}$ & 25.9 \\
\hline
\end{tabular}

\footnotetext{
${ }^{\mathrm{a}-\mathrm{c}}$ Within rows, means with different letter superscripts are different $(P<0.05)$.

${ }^{1}$ Treatments: Cows were fed from $256 \mathrm{~d}$ of pregnancy a dry cow ration and postpartum were fed a lactating cow diet (control); propylene glycol (PGLY); prilled fat:control (PrFA:control); PrFA:PrFA; calcium soaps of long-chain fatty acids:control (CaLFA:control); or CaLFA:CaLFA.
}

all number $\left(\mathrm{E}_{2}\right.$-active and $\mathrm{E}_{2}$-inactive) of follicles $\geq 6$ $\mathrm{mm}$ at 12 DIM in the CaLFA:CaLFA group was higher than in the control, PrFA:PrFA, and CaLFA:control groups $[1.6$ vs. $1.2,1.2$, and $1.2(\mathrm{SEM}=0.1)$, respectively; $P<0.03$ ]; however, the number of $\mathrm{E}_{2}$-active follicles at 12 DIM did not differ among groups (Table 6). The diameters and volumes of the $\mathrm{E}_{2}$-active follicles are presented in Table 6. The diameters of follicles that were aspirated at 12 DIM in the PrFA:control and CaLFA:control groups were smaller than those of the control group $(P<0.04)$.

The concentrations and contents of $\mathrm{P}_{4}, \mathrm{~A}_{4}$, and $\mathrm{E}_{2}$ in $\mathrm{FF}$ of the $\mathrm{E}_{2}$-active follicles are presented in Table 6 . The $\mathrm{P}_{4}$ concentrations were higher in $\mathrm{FF}$ of the CaLFA:CaLFA group than in all other groups $(P<0.04)$. The $\mathrm{A}_{4}$ concentrations in FF were higher in the CaLFA:CaLFA group than in the PGLY, PrFA:control, and CaLFA:control groups $(P<0.05)$, but were not different from those of the control and PrFA:PrFA groups. Estradiol concentrations in the FF were higher in the CaLFA:CaLFA group than in the PGLY, PrFA:control, and CaLFA:control groups $(P<0.008)$. The highest $\mathrm{P}_{4}$ content in $\mathrm{E}_{2}$-active follicles was in the CaLFA:CaLFA group and was higher than in the PrFA:control group $(P<0.05)$, yet no differences were observed among groups in the $\mathrm{A}_{4}$ and $\mathrm{E}_{2}$ contents in $\mathrm{E}_{2}$-active follicles.

\section{DISCUSSION}

In this study, we showed that different peripartum supplements influenced early PP intake, milk production, EB, and plasma metabolites. Feeding fat high or low in unsaturated FA to dry cows from late pregnancy until calving showed interesting differences in early PP period performance. Monitoring the follicular development during early PP resulted in no differences among groups. Nevertheless, peripartum supplementation of unsaturated FA affected FF steroid hormone concentrations in $\mathrm{E}_{2}$-active follicles that were aspirated at 12 DIM.

\section{DMI and Production}

Feeding fat to dairy cows was previously shown to decrease the DMI in some reports, whereas no changes were observed in others (Beam and Butler, 1998; Moallem et al., 2000). In the current study, the prepartum DMI of both fat-supplemented groups (PrFA and CaLFA) were lower than those in the control and PGLY groups (data not shown). In the same manner, the PP DMI to 21 DIM in the 2 groups that continued with fat supplementation PP were lower than that of the control group, and DMI of the CaLFA:CaLFA group was lower than that of the PGLY group. These results are in agreement with Beam and Butler (1998), who showed that addition of $2.6 \%$ fat from calving to 100 DIM decreased DMI by $11 \%$ in the first 4 wk of lactation as compared with a control group. In our study, although PP fat supplementation accounted for only $1 \%$ of the diet (DM basis), the DMI during the first $3 \mathrm{wk}$ PP in both fat-supplemented groups was decreased by $7.3 \%$ as compared with the control group.

\section{Plasma Metabolites}

The PP plasma glucose concentrations of the PGLY group were similar to those of the control group and were higher than in all other groups. An increase in plasma glucose concentrations when PGLY was fed was reported by others (Miyoshi et al., 2001), but Ballard et al. (2001), when feeding a supplement that contained $17 \%$ PGLY and $41 \%$ NSC to cows PP, reported no effects on plasma glucose concentrations as compared with a control group. Likewise, we found no differences in plasma glucose, NEFA, BHBA, and insulin concentrations between the control and PGLY groups.

The PP plasma BHBA concentrations were higher in the PrFA:control, PrFA:PrFA, and CaLFA:CaLFA groups as compared with the control and PGLY groups. Choi and Palmquist (1996) reported no effects of fat supplementation on plasma BHBA concentrations 

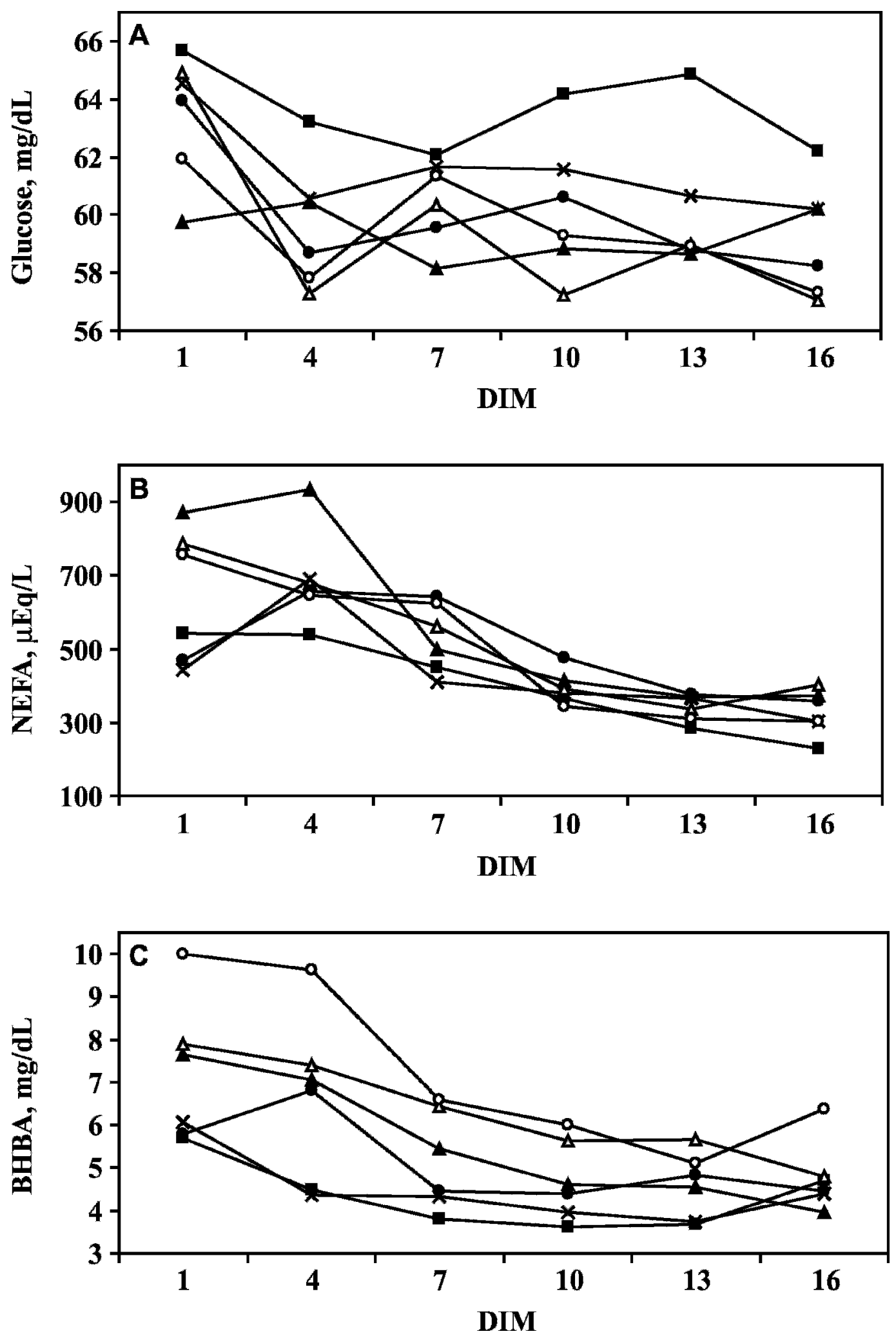

Figure 2. Least squares means of plasma concentrations of glucose (A), NEFA (B), and BHBA (C) to 17 DIM of cows fed from $256 \mathrm{~d}$ of pregnancy a dry cow ration and postpartum fed a lactating cow diet: control (x); propylene glycol (PGLY, $\square$ ); prilled fat:control (PrFA:control, $\Delta$ ); PrFA:PrFA ( $\triangle$ ); calcium soaps of long-chain fatty acids:control (CaLFA:control), ๑); or CaLFA:CaLFA (O). Pooled SEM values were 1.2 $\mathrm{mg} / \mathrm{dL}, 62.2 \mu \mathrm{Eq} / \mathrm{L}$, and $0.4 \mathrm{mg} / \mathrm{dL}$, for glucose, NEFA, and BHBA, respectively. 


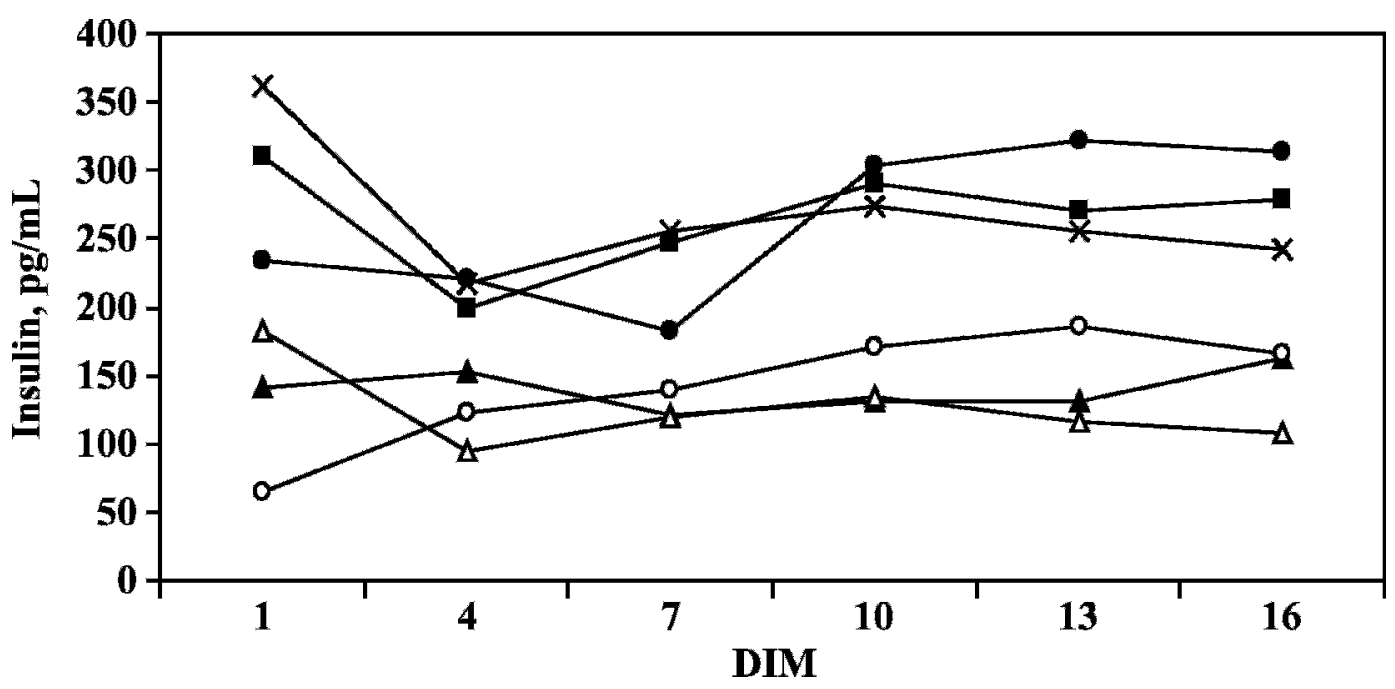

Figure 3. Least squares means of plasma concentrations of insulin to 16 DIM of cows fed from $256 \mathrm{~d}$ of pregnancy a dry cow ration and postpartum fed a lactating cow diet: control ( $\times$ ); propylene glycol (PGLY, $\mathbf{\square})$; prilled fat:control (PrFA:control, $\mathbf{\Delta})$; $\operatorname{PrFA:PrFA}(\triangle)$ ); calcium soaps of long-chain fatty acids:control (CaLFA:control, $)$ ); or CaLFA:CaLFA (O). The pooled SEM value was $26.0 \mathrm{pg} / \mathrm{mL}$.

when fat was fed to cows after the peak of lactation. In another report by Petit and Palin (2004), feeding prilled fat to cows from 6 wk prepartum to 4 wk PP resulted in higher plasma BHBA concentrations only in wk 2 and 4 PP compared with the control group. In studies in which fats were supplemented prepartum and PP, the increase in plasma BHBA concentrations was coincident with an increase in plasma NEFA concentrations (Petit and Palin, 2004). In the present study, higher plasma NEFA concentrations were observed in a manner very similar to BHBA in the PrFA:PrFA and CaLFA:CaLFA groups, compared with the control group. Moreover, a significant correlation was found between plasma NEFA and BHBA concentrations $(r=$ 0.38; $P<0.0001)$. The data of Grummer and Carroll (1991) indicated that plasma NEFA concentrations were almost always elevated because of fat feeding, whereas the plasma BHBA responses were inconsistent. Their findings could explain the inconsistent relationship between plasma NEFA and BHBA concentrations in response to fat supplementation. Nonesterified FA generally originate from body fat mobilization and then infiltrate the liver. The final oxidation of NEFA in the hepatocytes depends on other substrates such as propionate (Drackley, 1999). When NEFA availability in the liver exceeds the oxidation capacity of the hepato-

Table 6. Follicle size and concentrations and amounts of progesterone, androstenedione, and estradiol of estradiol-active ( $\mathrm{E}_{2}$-active) follicles $>6 \mathrm{~mm}$, aspirated at $12 \mathrm{DIM}$

\begin{tabular}{|c|c|c|c|c|c|c|c|}
\hline \multirow[b]{2}{*}{ Item } & \multicolumn{6}{|c|}{ Treatment $^{1}$} & \multirow[b]{2}{*}{ SEM } \\
\hline & Control & PGLY & $\begin{array}{l}\text { PrFA: } \\
\text { control }\end{array}$ & $\begin{array}{l}\text { PrFA: } \\
\text { PrFA }\end{array}$ & $\begin{array}{l}\text { CaLFA: } \\
\text { control }\end{array}$ & $\begin{array}{l}\text { CaLFA: } \\
\text { CaLFA }\end{array}$ & \\
\hline Cows, ${ }^{2} \mathrm{n}$ & 10 & 8 & 10 & 10 & 11 & 9 & \\
\hline Follicles ( $\mathrm{E}_{2}$-active), $\mathrm{n}$ & 10 & 12 & 13 & 10 & 13 & 13 & \\
\hline Diameter, $\mathrm{cm}$ & $1.3^{\mathrm{a}}$ & $1.1^{\mathrm{ab}}$ & $1.0^{\mathrm{b}}$ & $1.2^{\mathrm{ab}}$ & $1.0^{\mathrm{b}}$ & $1.1^{\mathrm{ab}}$ & 0.1 \\
\hline Volume, mL & 1.3 & 0.8 & 0.7 & 1.3 & 0.7 & 0.8 & 0.2 \\
\hline Progesterone, ng/mL & $92.4^{\mathrm{b}}$ & $71.1^{\mathrm{b}}$ & $68.9^{\mathrm{b}}$ & $57.3^{\mathrm{b}}$ & $70.1^{\mathrm{b}}$ & $200.7^{\mathrm{a}}$ & 36.4 \\
\hline Androstenedione, $\mathrm{ng} / \mathrm{mL}$ & $33.2^{\mathrm{ab}}$ & $15.5^{\mathrm{b}}$ & $22.6^{\mathrm{b}}$ & $29.9^{\mathrm{ab}}$ & $17.5^{\mathrm{b}}$ & $54.2^{\mathrm{a}}$ & 12.1 \\
\hline Estradiol, $\mathrm{ng} / \mathrm{mL}$ & $670.6^{\mathrm{ab}}$ & $440.1^{\mathrm{b}}$ & $314.1^{\mathrm{b}}$ & $720.8^{\mathrm{ab}}$ & $451.9^{\mathrm{b}}$ & $1,049.1^{\mathrm{a}}$ & 163.2 \\
\hline Total progesterone, ng & $114.7^{\mathrm{ab}}$ & $72.3^{\mathrm{ab}}$ & $54.2^{\mathrm{b}}$ & $73.8^{\mathrm{ab}}$ & $64.8^{\mathrm{ab}}$ & $172.1^{\mathrm{a}}$ & 43.9 \\
\hline Total androstenedione, ng & 55.2 & 9.3 & 24.9 & 51.9 & 13.6 & 64.5 & 26.2 \\
\hline Total estradiol, ng & 977.0 & 408.3 & 333.0 & $1,264.0$ & 445.2 & $1,057.4$ & 352.2 \\
\hline
\end{tabular}

\footnotetext{
${ }^{\mathrm{a}, \mathrm{b}}$ Within rows, means with different superscripts are different $(P<0.05)$.

${ }^{1}$ Treatments: Cows were fed from $256 \mathrm{~d}$ of pregnancy a dry cow ration and postpartum were fed a lactating cow diet (control); propylene glycol (PGLY); prilled fat:control (PrFA:control); PrFA:PrFA; calcium soaps of long-chain fatty acids:control (CaLFA:control); or CaLFA:CaLFA.

${ }^{2}$ Cows with successful aspiration and at least one $\mathrm{E}_{2}$-active follicle.
} 
cytes, NEFA are converted to ketone bodies such as BHBA. The elevation in plasma BHBA concentrations in response to fat supplementation seems to depend on the metabolic status of the cow; during the transition period when plasma NEFA concentrations increase, there is a higher probability of a coincident increase in plasma BHBA concentrations than later in lactation. Further research is needed to elucidate the relationship between NEFA and BHBA in the transition dairy cow.

The plasma insulin concentrations in the PrFA:control, PrFA:PrFA, and CaLFA:CaLFA groups were lower than in those in the control and PGLY groups, in agreement with another study that reported a decrease in plasma insulin concentrations in response to fat supplementation (Choi and Palmquist, 1996). The decrease in plasma insulin concentrations with fat supplementation seems to be a direct effect rather than through a decrease in DMI.

Interesting differences were found in PP plasma metabolites between cows that were fed only PrFA prepartum and those fed CaLFA. Generally, the cows in the PrFA:control group showed plasma concentrations of glucose, NEFA, BHBA, and insulin similar to those in the PrFA:PrFA and CaLFA:CaLFA groups, whereas the plasma concentrations of NEFA, BHBA, and insulin in the CaLFA:control group were similar to those in the control and PGLY groups. The ability of specific FA to regulate gene expression, enzyme activities, and other cell biochemical pathways was reported previously (Drackley, 1999). In the current study, although no significant differences were observed in plasma metabolites between both continuous fat-supplemented groups, the differences between the prepartum fat-supplemented groups (PrFA:control and CaLFA:control) may indicate differences in carryover effects of feeding saturated or unsaturated FA.

\section{Early PP Follicle Dynamics and Quality}

Several studies have investigated follicular development at early lactation. Beam and Butler (1998) examined follicular development at early lactation in cows that were fed PrFA and reported no differences compared with a control group. Our results, in which no differences were observed among groups in the appearance of follicles $\geq 6 \mathrm{~mm}$ during 8 to $12 \mathrm{DIM}$, are in agreement with their findings. The across-treatment average number of follicles $\geq 6 \mathrm{~mm}$ at 8 DIM in this study was 1.6 follicles/cow, which was similar to that reported by Lucy et al. (1991) at 7 DIM and by Beam and Butler (1998) from 8 to 14 DIM. Across-treatment data showed no significant relationship between the average calculated EB during the first $12 \mathrm{~d}$ of lactation and the number of follicles $\geq 6 \mathrm{~mm}$. Similar results were reported by Beam and Butler (1997), in which no significant correlation was observed between the number of 6- to 9-mm follicles and EB. Analyses of $\mathrm{P}_{4}$ and $\mathrm{E}_{2}$ of follicles $\geq 6 \mathrm{~mm}$ at $12 \mathrm{DIM}$ indicated that $79 \%$ were $\mathrm{E}_{2}$-active and $21 \%$ were $\mathrm{E}_{2}$-inactive, with no differences among groups. There was no significant relationship between the average calculated EB during the first 12 $\mathrm{d}$ of lactation and the concentrations of $\mathrm{E}_{2}$ or $\mathrm{P}_{4}$ in $\mathrm{FF}$ of $\mathrm{E}_{2}$-active follicles.

This is the first known study in which the hormone status of medium to large ovarian follicles in dairy cows with different dietary supplementations was determined during the early PP period. No significant differences were observed among groups in the number of $\mathrm{E}_{2^{-}}$ active follicles at 12 DIM. But differences were observed among treatments in the $\mathrm{P}_{4}, \mathrm{~A}_{4}$, and $\mathrm{E}_{2}$ concentrations in FF. Collectively with the data of Lucy et al. (1991) and Beam and Butler (1997), the degree of negative EB seems to have a minor influence on follicular development in the ovaries during the early PP period. Previously, Moallem et al. (2000) observed no differences among groups in the initiation of plasma $\mathrm{P}_{4}$ cyclicity, in spite of differences in all EB parameters. Moreover, Lucy et al. (1991) found a weak relationship between $\mathrm{EB}$ and first ovulation, indicating that the interval to first ovulation might be influenced by other factors more than by EB.

The results in the current study suggest that the adverse effects of EB on follicle quality at early lactation in high-producing dairy cows could be diminished by nutritional means. The highest $\mathrm{P}_{4}$ concentrations in $\mathrm{E}_{2^{-}}$ active follicles $\geq 6 \mathrm{~mm}$ at 12 DIM was achieved in the CaLFA:CaLFA group, although the average EB during the first $12 \mathrm{~d}$ of lactation in this group was lower than in the control group. Similar results were reported by Moallem et al. (1999), in which higher steroid hormones were found in FF from cows that were fed calcium soap of FA compared with a control group, although no improvement in EB was observed. Staples et al. (1998) suggested that the FA profile of the dietary fat might have a major effect on steroidogenesis. Abayasekara and Wathes (1999) suggested that dietary fats lead to an increase in arachidonic acid in the phospholipids of ovarian granulosa cells through linoleic acid desaturation and elongation. The release of arachidonic acid from the phospholipids in response to gonadotropin stimulation could have a direct effect on steroidogenesis, or could be metabolized to prostaglandins such as prostaglandin $\mathrm{E}_{2}$, which is known as a steroidogenesis stimulator. Linoleic acid (18:2) is the precursor of arachidonic acid (20:4), and in our study the CaLFA contained 30.5\% linoleic acid. It might be that the increased availability of linoleic acid in the CaLFA:CaLFA group increased arachidonic acid synthesis, which led to in- 
creased steroidogenesis, as was suggested by Abayasekara and Wathes (1999) and Robinson et al. (2002).

Insulin was shown to be a stimulator of bovine follicular cells (Simpson et al., 1994). However, in the current study cows in the CaLFA:CaLFA group had lower plasma insulin concentrations, coincident with higher $\mathrm{P}_{4}, \mathrm{~A}_{4}$, and $\mathrm{E}_{2}$ concentrations in $\mathrm{FF}$ compared with the PGLY and CaLFA:control groups. These findings suggest that dietary supplementation of unsaturated FA could have positive effects on follicle substrates in a direct manner rather than by improving the energy supply and EB status of the cows or through increased insulin concentrations.

\section{CONCLUSIONS}

Supplementing the diets of dairy cows with PrFA or CaLFA from $256 \mathrm{~d}$ of pregnancy to 21 DIM decreased DMI and negatively affected the EB, which was also reflected in higher plasma BHBA and NEFA concentrations compared with cows not fed fat. Differences between the PrFA:control and CaLFA:control groups were observed in milk production, DMI, plasma NEFA, and plasma insulin concentrations.

Early PP follicular development, as determined by the number of follicles $\geq 6 \mathrm{~mm}$ at 8,10 , and $12 \mathrm{DIM}$, was similar among all groups. Moreover, no significant relationships were found between the calculated EB during the first 12 DIM and the FF concentrations of $\mathrm{P}_{4}$ or $\mathrm{E}_{2}$ in $\mathrm{E}_{2}$-active follicles at 12 DIM. Nevertheless, we found that feeding unsaturated FA to cows during the prepartum and $\mathrm{PP}$ periods significantly increased the $\mathrm{FF} \mathrm{P}_{4}$ concentrations in $\mathrm{E}_{2}$-active follicles at 12 DIM, as compared with the control group. These findings suggest that dietary supplementation of unsaturated FA could have direct positive effects on follicle substrates during the early PP period, rather than by improving the EB status of the cows.

\section{ACKNOWLEDGMENTS}

The authors gratefully acknowledge the kind donation of Megalac-R by Church \& Dwight (Princeton, NJ), and Energy Booster 100 by Milk Specialties (Dundee, IL). We also thank the experimental dairy farm team at the Volcani Center (Bet Dagan, Israel) for their assistance with animal care. This research was supported by Research Grant No. US-3422-03 R from BARD, The United States-Israel Binational Agricultural Research and Development Fund.

\section{REFERENCES}

Abayasekara, D. R. E., and D. C. Wathes. 1999. Effects of altering dietary fatty acid composition on prostaglandin synthesis and fertility. Prostaglandins Leukot. Essent. Fatty Acids 61:275-287.
AOAC. 1990. Official Methods of Analysis. Association of Official Analytical Chemists, Arlington, VA.

Ballard, C., P. Mandebvu, C. J. Sniffen, S. M. Emanuele, and M. P. Carter. 2001. Effect of feeding an energy supplement to dairy cows pre- and postpartum on intake, milk yield, and incidence of ketosis. Anim. Feed Sci. Technol. 93:55-59.

Beam, S. W., and W. R. Butler. 1997. Energy balance and ovarian follicle development prior to the first ovulation postpartum in dairy cows receiving three levels of dietary fat. Biol. Reprod. 56:133-142.

Beam, S. W., and W. R. Butler. 1998. Energy balance, metabolic hormones and early postpartum follicular development in dairy cows fed prilled lipid. J. Dairy Sci. 81:121-131.

Beam, S. W., and W. R. Butler. 1999. Effects of energy balance on follicular development and first ovulation in postpartum dairy cows. J. Reprod. Fertil. Suppl. 54:411-424.

Bremmer, D. R., L. D. Ruppert, J. H. Clark, and J. K. Drackley. 1998. Effects of chain length and unsaturation of fatty acid mixtures infused into the abomasum of lactating dairy cows. J. Dairy Sci. $81: 176-188$.

Christensen, J. O., R. R. Grummer, F. E. Rasmussen, and S. J. Bertics. 1997. Effect of method of delivery of propylene glycol on plasma metabolites of feed-restricted cattle. J. Dairy Sci. 80:563-568.

Choi, B. R., and D. L. Palmquist. 1996. High fat diets increase plasma cholecystokinin and pancreatic polypeptide, and decrease plasma insulin and feed intake in lactating cows. J. Nutr. 126:2913-2919.

Drackley, J. K. 1999. Biology of dairy cows during the transition period: The final frontier? J. Dairy Sci. 82:2259-2273.

Drackley, J. K., T. H. Klusmeyer, A. M. Trusk, and J. H. Clark. 1992. Infusion of long-chain fatty acids varying in saturation and chain length into the abomasum of lactating dairy cows. J. Dairy Sci. $75: 1517-1526$.

Grummer, R. R., and D. J. Carroll. 1991. Effects of dietary fat on metabolic disorders and reproductive performance of dairy cattle. J. Anim. Sci. 69:3838-3852.

Hoedemaker, M., D. Prange, H. Zerbe, J. Frank, A. Daxenberger, and H. H. D. Meyer. 2004. Peripartal propylene glycol supplementation and metabolism, animal health, fertility, and production in dairy cows. J. Dairy Sci. 87:2136-2145.

Jorritsma, R., M. L. Cesar, J. T. Hermans, C. L. J. J. Kruitwagen, P. L. A. M. Vos, and T. A. M. Kruip. 2004. Effects of non-esterified fatty acids on bovine granulose cells and developmental potential of oocytes in vitro. Anim. Reprod. Sci. 81:225-235.

Jorritsma, R., H. Jorritsma, Y. H. Schukken, and G. H. Wentink. 2000. Relationships between fatty liver and fertility and some periparturient diseases in commercial Dutch dairy herds. Theriogenology 54:1065-1074.

Lucy, M. C., C. R. Staples, F. M. Michel, and W. W. Thatcher. 1991. Energy balance and size and number of ovarian follicles detected by ultrasonography in early postpartum dairy cows. J. Dairy Sci. 74:473-482.

Mattos, R., C. R. Staples, and W. W. Thatcher. 2000. Effects of dietary fatty acids on reproduction in ruminants. Rev. Reprod. 5:38-45.

Miyoshi, S., J. L. Pate, and D. L. Palmquist. 2001. Effects of propylene glycol drenching on energy balance, plasma glucose, plasma insulin, ovarian function and conception in dairy cows. Anim. Reprod. Sci. 68:29-43.

Moallem, U., Y. Folman, A. Bor, A. Arav, and D. Sklan. 1999. Effect of calcium soaps of fatty acids and administration of somatotropin on milk production, preovulatory follicular development, and plasma and follicular fluid lipid composition in high yielding dairy cows. J. Dairy Sci. 82:2358-2368.

Moallem, U., Y. Folman, and D. Sklan. 2000. Effects of somatotropin and dietary calcium soaps of fatty acids in early lactation on milk production, dry matter intake, and energy balance of highyielding dairy cows. J. Dairy Sci. 83:2085-2094.

Moallem, U., M. Kaim, Y. Folman, and D. Sklan. 1997. Effect of calcium soaps of fatty acids and administration of somatotropin in early lactation on productive and reproductive performance of high producing dairy cows. J. Dairy Sci. 80:2127-2136.

NRC. 2001. Nutrient Requirements of Dairy Cattle. 7th rev. ed. Natl. Acad. Sci., Washington, DC. 
Petit, H., and M. F. Palin. 2004. Carbohydrate and lipid metabolism in the transition dairy cow fed linseed. J. Anim. Feed Sci. 13 (Suppl. 1) 651-654.

Robinson, R. S., P. G. A. Pushpakumara, Z. Cheng, A. R. Peters, D. R. Abayasekara, and D. C. Wathes. 2002. Effects of dietary polyunsaturated fatty acids on ovarian and uterine function in lactating dairy cows. Reproduction 124:119-131.

SAS Institute. 2000. SAS User's Guide: Statistics. Version 8.1 Edition. SAS Inst. Inc., Cary, NC.
Simpson, R. B., C. C. Chase, Jr., L. J. Spicer, R. K. Vernon, A. C. Hammond, and D. O. Rae. 1994. Effects of exogenous insulin on plasma and follicular insulin-like growth factor 1, insulin-like growth factor binding protein activity, follicular oestradiol and progesterone, and follicular growth in superovulated Angus and Brahman cows. J. Reprod. Fertil. 102:483-492.

Staples, C. R., J. M. Burke, and W. W. Thatcher. 1998. Influence of supplemental fats on reproductive tissues and performance of lactating cows. J. Dairy Sci. 81:856-871. 